\title{
Uso do Farelo de Vagem de Algaroba (Prosopis juliflora (Swartz) D.C.) em Dietas para Eqüinos ${ }^{1}$
}

\section{Rosane Barros da Silva Stein ${ }^{2}$, Luiz Roberto Aguiar de Toledo ${ }^{3}$, Fernando Queiroz de Almeida ${ }^{4}$, Ana Cristina Arnaut ${ }^{5}$, Liliane Teixeira Patitucci ${ }^{5}$, João Soares Neto ${ }^{6}$, Viviane Tibau Mesquita da Costa ${ }^{7}$}

\begin{abstract}
RESUMO - Este trabalho foi conduzido para se avaliar o uso do farelo de vagem de algaroba (FVA) em substituição ao milho desintegrado com palha e sabugo (MDPS) sobre o consumo de nutrientes em dietas para eqüinos. Foram utilizadas 16 éguas da raça Mangalarga Marchador, com idade variando de 3,5 a 18,4 anos e peso médio de 394,8 kg. No ensaio de digestão, foi utilizado o método da coleta total de fezes e foram estimados os coeficientes de digestibilidade aparente da matéria seca (CDMS), matéria orgânica(CDMO), proteína bruta (CDPB), fibra em detergente neutro (CDFDN), hemicelulose (CDHCEL), fibra em detergente ácido (CDFDA) e energia bruta (CDEB). As dietas, isoprotéicas e isocalóricas, foram compostas de feno de coastcross e concentrado na proporção de 60:40. Os níveis de substituição do MDPS pelo FVA foram de 0,33, 66 e 100\%. O delineamento experimental adotado foi em blocos casualizados (idade das éguas), com quatro repetições por tratamento. Não houve efeito dos blocos nas variáveis avaliadas. O consumo de matéria seca não foi afetado pela inclusão do FVA, observando-se valores médios de 1,8\% do peso vivo (PV), 7,02 kg MS/dia, 79,84 g MS/kg PV 0,75 . Os CDMS, CDMO, CDPB e CDHCEL não diferiram entre as dietas experimentais, com valores médios de 49,15, 50,18, 56,89 e 35,43\%, respectivamente. Verificou-se efeito linear decrescente no CDFDN e quadrático no CDFDA e CDEB, em função dos níveis crescentes de substituição. De acordo com as equações de regressão, o valor máximo do CDFDA seria obtido com $22,3 \%$ de substituição, enquanto os valores do CDFDN e CDEB seriam máximos na dieta sem o FVA. Conclui-se que, apesar da redução no aproveitamento das frações fibrosas das dietas, o FVA pode ser utilizado em dietas para eqüinos.
\end{abstract}

Palavras-chave: digestão, eqüinos, Prosopis juliflora

\section{Effects of Feeding Mesquite Pod Meal (Prosopis juliflora (Swartz) D.C.) for Horses}

\begin{abstract}
Sixteen mares of Mangalarga Marchador breed, averaging from 3.5 to 18.4 years old and $394.8 \mathrm{~kg}$, were assigned to a randomized blocks (mares age) design, with four replicates by treatment, to evaluate the effects of replacing corn cob meal (CCM) with mesquite pod meal (MPM) on nutrient intake. In the digestion trial, the total feces collection method was used and the coefficients of apparent digestibility of dry matter (CDDM), organic matter (CDOM), crude protein (CDCP), acid detergent fiber (CDADF), neutral detergent fiber (CDNDF), hemicellulose (CDHCEL) and gross energy (CDGE) were estimated. Diets were formulated to be isonitrogenous and isoenergetic, all containing coastcross hay and concentrate (60:40 ratio). The treatments consisted of increasing replacement levels of CCM with MPM, as follows: 0, 33, 66 and $100 \%$. No effects of mare age on the variables were detected. No significant effect of increasing MPM levels on dry matter intake, with mean values of $1.8 \%$ body weight (BW), $7.02 \mathrm{~kg} \mathrm{DM} /$ day, $79.84 \mathrm{~g} \mathrm{DM} / \mathrm{kg} \mathrm{BW}^{0.75}$, was observed. CDDM, CDOM, CDCP and CDHCEL did not differ among diets and showed the respective mean values of 49.15, 50.18, 56.89, and 35.43\%. Linear decreasing effect on CDNDF and quadratic effect on CDADF and CDGE were observed as the dietary levels of MPM increased. According to the regression equations, maximum point of CDADF could be obtained by replacing 22.3\% MPM and maximum values of CDNDF and CDGE in the diets without MPM. It was concluded that, despite of decrease on dietary fiber digestibility, mesquite pod meal can be used in horses diets.
\end{abstract}

Key Words: digestion, horses, Prosopis juliflora

\section{Introdução}

A algarobeira é uma leguminosa arbórea que concentra o seu valor nutritivo nas vagens (frutos), constituindo-se rica fonte de carboidratos e proteínas, com valor energético bruto comparável ao milho. É encontrada em toda a região Nordeste do Brasil, desenvolvendo-se com invejável capacidade desde praças até fazendas que já se beneficiam de suas propriedades nutricionais na criação animal.

\footnotetext{
${ }^{1}$ Parte da dissertação de mestrado apresentada à Faculdade de Zootecnia e Engenharia de Alimentos - USP pelo primeiro autor. Projeto financiado pela FAPESP.

2 Zootecnista, MSc. End.: R.Luiz Massari, 77, Jd. São Paulo, Limeira-SP. E.mail: rbsstein@terra.com.br

${ }^{3}$ Prof. Dr. Faculdade de Zootecnia e Engenharia de Alimentos - USP. E.mail: Iratoled@usp.br

4 Prof. Dr. Universidade Federal Rural do Rio de Janeiro. Bolsista PQ II CNPq. E.mail: falmeida@ufrrj.br

5 Discente de Graduação em Medicina Veterinária. Bolsista de Iniciação Científica PIBIC/CNPq - UFRRJ

6 Discente de Graduação em Zootecnia - UFRRJ. Bolsista de Iniciação Científica FAPERJ.

7 Discente de Graduação em Zootecnia da UFRRJ.
} 
Estudos sobre a utilização da algaroba para várias espécies como bovinos, ovinos, suínos, aves, têm sido desenvolvidos com o objetivo de tornar viável sua inclusão em rações, bem como minimizar os custos da produção animal. Talpada \& Shukla (1988) não observaram diferenças nos coeficientes de digestibilidade dos nutrientes de dietas para vacas lactantes com níveis de inclusão da vagem de algaroba triturada em até 30\%, enquanto Barros \& Queiróz Filho (1982), em pesquisas com carneiros, utilizaram vagem de algaroba em substituição ao melaço, em dietas à base de farelo de algodão, melaço, uréia e capim-elefante e não observaram efeitos sobre a digestibilidade da matéria seca, proteína bruta e energia bruta.

Nobre (1982) evidenciou maior eficiência de produção de leite ao empregarem a vagem de algaroba triturada em substituição, em até $60 \%$, ao farelo de trigo na dieta de vacas em lactação, assim como Silva et al. (1982) observaram desempenho semelhante no ganho de peso de bovinos de corte em confinamento alimentados com dietas contendo até $100 \%$ de vagem de algaroba triturada em substituição ao farelo de trigo.

Em herbívoros, fatores determinantes da extensão da utilização de fibras no sistema digestivo são o tempo de retenção disponível e a eficiência da fermentação microbiana (De Fombelle et al., 1999). Neste aspecto, encontra-se uma das principais diferenças na utilização das fontes fibrosas entre eqüinos e ruminantes. A menor capacidade de utilização digestiva de fenos fibrosos em eqüinos está relacionada à população e à atividade celulolítica da microflora ceco-cólica, sendo os fenos fibrosos menores em relação aos bovinos (Frape, 1986; Cymbaluk, 1990). Os valores de digestibilidade da matéria orgânica e da fibra bruta em cavalos alimentados com teores maiores que $15 \%$ de $\mathrm{FB}$ foram aproximadamente 85 e, 70 a $75 \%$, respectivamente, dos valores estimados para ruminantes (Frape, 1986).

Gomes (1961) recomenda consumo de 2 a $6 \mathrm{~kg}$ diários de vagem de algaroba, por eqüinos e muares, enquanto Martin-Rosset (1993) relata que cavalos podem consumir cerca de $1,2 \mathrm{~kg} / 100 \mathrm{~kg}$ de $\mathrm{PV} / \mathrm{dia}$ desse fruto, muito apreciado por estes animais.

Conduziu-se este trabalho para avaliar o consumo de nutrientes e o valor nutricional do farelo de vagem triturada de algaroba em substituição ao milho desintegrado com palha e sabugo (MDPS), em dietas para eqüinos por meio de ensaio de digestão.

\section{Material e Métodos}

O experimento foi conduzido no Setor de Eqüinocultura do Instituto de Zootecnia da Universidade Federal Rural do Rio de Janeiro (UFRRJ), em Seropédica, RJ ( $22^{\circ} 45^{\prime} \mathrm{S}$ e $43^{\circ} 41^{\prime} \mathrm{W}$ e altitude $\left.33 \mathrm{~m}\right)$. Os dados meteorológicos no período de 01 a 30 de junho de 2001 registraram temperaturas máxima, mínima e média, respectivamente, de 26,8, 16,8 e $21,0^{\circ} \mathrm{C}$, umidade relativa de $68,7 \%$ e precipitação pluviométrica de $15,3 \mathrm{~mm}$.

As análises bromatológicas foram efetuadas nos Laboratórios de Bromatologia do Departamento de Zootecnia da Faculdade de Zootecnia e Engenharia de Alimentos - Universidade de São Paulo (FZEA - USP).

Foram utilizadas 16 éguas da raça Mangalarga Marchador, com idade entre 3,5 e 18,4 anos e peso de $394,8 \pm 42,66 \mathrm{~kg}$. Os animais foram alojados em baias individuais, de $3,5 \mathrm{~m} \times 3,0 \mathrm{~m}$, providas de piso de cimento, sem cama, com comedouros para concentrado, volumoso, sal e bebedouro tipo balde.

O experimento teve duração de 26 dias e foi composto de um período de 21 dias para adaptação e avaliação de consumo voluntário (Fase I) e de cinco dias para colheita de fezes (Fase II), visando estimar os coeficientes de digestibilidade aparente da matéria seca, matéria orgânica, proteína bruta, fibra em detergente neutro, hemicelulose, fibra em detergente ácido e energia bruta, utilizando-se as equações propostas por Merchen (1993).

A quantidade de alimento fornecido aos animais foi estabelecida segundo as recomendações do NRC (NRC, 1989), visando atender às exigências nutricionais para a categoria. No início da fase de adaptação, os animais receberam dietas equivalentes a $1,7 \%$ do seu peso vivo, em matéria seca ao ar, constituídas de $60 \%$ feno de Coast cross (Cynodon dactylon cv. Coast cross) picado e $40 \%$ de concentrado. Em seguida, a alimentação foi fornecida ad libitum, mantendo-se a proporção volumoso:concentrado, para que houvesse avaliação de consumo, e, no período de colheita, fossem evitadas sobras.

Os tratamentos consistiram de quatro rações concentradas contendo quatro diferentes níveis de farelo de vagem de algaroba $(0,25,50$ e $75 \%)$, em substituição ao milho desintegrado com palha e sabugo (MDPS). A substituição ocorreu em relação ao peso dos ingredientes, visto que foi fixada a quantidade 
máxima do MDPS e/ou farelo de vagem de algaroba na ração concentrada em $75 \%$. Portanto, a substituição do MDPS pelo farelo de vagem de algaroba foi equivalente a $0,33,66$ e 100\%. A composição dos concentrados pode ser observada na Tabela 1 .

As quantidades de ração concentrada e de feno foram fornecidas individualmente, três vezes ao dia, às $8 \mathrm{~h}, 13 \mathrm{~h}$ e $18 \mathrm{~h}$ e, as sobras retiradas diariamente. Amostras das dietas, do feno e das sobras foram coletadas e, no final do período de avaliação de consumo, foram compostas do período para cada animal. As amostras foram separadas em alíquotas proporcionais, para secagem em estufa de ventilação forçada a $65^{\circ} \mathrm{C}$, por 48 horas, sendo posteriormente processadas em moinho com peneira de $1 \mathrm{~mm}^{2}$ para as análises laboratoriais.

Para obtenção do consumo real dos nutrientes, consideram-se as médias de consumo de feno, de concentrado e das sobras de cada animal, segundo a equação:

$$
C R N=\frac{(C c \times N c+C f \times N f)-S \times N S}{100}
$$

em que: $\mathrm{CRN}=$ consumo real do nutriente $(\mathrm{g}$ na $\mathrm{MS})$; $\mathrm{Cc}=$ quantidade de concentrado consumida ( $\mathrm{g}$ na $\mathrm{MS}) ; \mathrm{Nc}=$ concentração do nutriente no concentrado $(\%$ na $\mathrm{MS}) ; \mathrm{Cf}=$ quantidade de feno consumida $(\mathrm{g}$ na
$\mathrm{MS}$ ); Nf = concentração do nutriente no feno (\% na $\mathrm{MS}) ; \mathrm{S}=$ sobra média calculada no período de coleta ( $\mathrm{g}$ na MS); Ns = concentração do nutriente nas sobras (\% na MS).

$\mathrm{Na}$ fase II, as fezes foram colhidas diretamente do piso, acondicionadas em baldes plásticos identificados por animal e pesadas nos seguintes horários: 13, 18, 24 e $8 \mathrm{~h}$. Após homogeneização e pesagem, foram retiradas alíquotas de $10 \%$ da produção fecal avaliada no período, fazendo-se amostras compostas de fezes ao final de cada dia, por animal, e após os cinco dias de coleta. Deste conteúdo, foram separadas alíquotas de $200 \mathrm{~g}$ para secagem em estufa de ventilação forçada a $65^{\circ} \mathrm{C}$, por 48 horas, que, posteriormente, foram processadas em moinho com peneira de $1 \mathrm{~mm}^{2}$ para as futuras análises laboratoriais.

As análises bromatológicas dos alimentos, das sobras e fezes para avaliar os teores da matéria seca (MS), matéria orgânica (MO), proteína bruta (PB), fibra em detergente neutro (FDN), fibra em detergente ácido (FDA), energia bruta (EB), cálcio (Ca) e fósforo (P) foram realizadas segundo Silva \& Queiroz (2002).

Para obtenção do farelo de vagem de algaroba, as vagens foram trituradas, secas em temperatura média de $60^{\circ} \mathrm{C}$, por aproximadamente 10 horas até atingirem 10 a $12 \%$ de umidade, e, seqüencialmente, moídas. O processamento foi descrito de forma detalhada por Stein (2002).

Tabela 1 - Composição centesimal e química (\% na MS) dos concentrados experimentais contendo diferentes níveis de substituição do MDPS pelo FVA

Table 1 - Chemical (\% DM) composition of the experimental concentrates with increasing replacement levels of CCM with MPM

\begin{tabular}{|c|c|c|c|c|}
\hline \multirow[t]{2}{*}{$\begin{array}{l}\text { Ingrediente } \\
\text { Ingredient }\end{array}$} & \multicolumn{4}{|c|}{$\begin{array}{c}\text { Níveis de substituição (\%) } \\
\text { Replacement levels }\end{array}$} \\
\hline & 0 & 33 & 66 & 100 \\
\hline MDPS (Corn cob meal, CCM) & 75,00 & 50,00 & 25,00 & 0,00 \\
\hline Farelo de vagem de algaroba (FVA) & 0,00 & 25,00 & 50,00 & 75,00 \\
\hline Mesquite pod meal (MPM) & & & & \\
\hline Farelo de soja (Soybean meal) & 7,28 & 6,72 & 6,64 & 3,32 \\
\hline Farelo de trigo (Wheat meal) & 14,73 & 14,11 & 15,85 & 19,07 \\
\hline Calcário calcítico (Limestone) & 1,99 & 3,17 & 1,51 & 1,61 \\
\hline Sal comum (Salt) & 1,00 & 1,00 & 1,00 & 1,00 \\
\hline Total & 100,00 & 100,00 & 100,00 & 100,00 \\
\hline $\mathrm{EB}(\mathrm{kcal} / \mathrm{kg})(G E)$ & 3504,3 & 3298,9 & 3404,3 & 3418,7 \\
\hline $\mathrm{PB}(C P)$ & 10,2 & 10,4 & 10,3 & 10,4 \\
\hline $\mathrm{FDN}(N D F)$ & 24,6 & 26,5 & 24,6 & 23,6 \\
\hline $\mathrm{FDA}(A D F)$ & 11,9 & 15,7 & 15,5 & 14,9 \\
\hline $\mathrm{Ca}$ & 0,78 & 1,20 & 0,78 & 0,93 \\
\hline $\mathrm{P}$ & 0,27 & 0,20 & 0,23 & 0,22 \\
\hline
\end{tabular}


O delineamento utilizado foi o de blocos casualizados (idades dos animais), com quatro repetições em cada tratamento. O bloco I foi composto por éguas de 3,5 a 5 anos de idade; o bloco II, por éguas de 5 a 9 anos; o bloco III, por éguas de 13 a 17 anos; o bloco IV, por éguas de 17 a 18,4 anos. Os dados foram submetidos a análises de variância e regressão, por intermédio do PROC GLM do programa STATISTICAL ANALYSIS SYSTEM (SAS, 1989), considerando resultados significativos a $5 \%$ de probabilidade.

\section{Resultados e Discussão}

A análise dos dados não demonstrou efeito da idade das éguas sobre nenhum dos parâmetros avaliados para consumo de nutrientes. Na Tabela 2, podem ser observados os valores médios de peso vivo e de consumo de matéria seca durante o período experimental. A substituição pelo FVA não alterou o consumo dos animais, que apresentou valores médios de 7,02 kg de MS/dia, 1,80\%PV e 79,84 g MS/kg PV ${ }^{0,75}$.

As éguas apresentaram boa aceitabilidade à dieta, não sendo observada nenhuma restrição de consumo decorrente da inclusão do FVA. A ingestão de matéria seca foi superior às recomendações do NRC (1989) para o peso médio observado, de $1,68 \% \mathrm{PV}$ ou $6,6 \mathrm{~kg} \mathrm{MS} / \mathrm{dia}$, para animais com $392,2 \mathrm{~kg}$, entretanto inferior aos $2 \%$ PV preconizados por Frape (1986) e Meyer (1995).

O feno oferecido aos animais caracterizou-se como de baixa qualidade, possuindo teor de PB de 4,5\% e elevados percentuais de FDN e FDA, de 67,7 e 36,9\%, respectivamente. Oliveira (1995) atribuiu o menor consumo observado para ração exclusiva de capim-elefante, em relação a rações contendo capim e $50 \%$ de milho triturado ou $35 \%$ de milho triturado e $15 \%$ de farelo de soja ao estádio vegetativo avançado do capim-elefante, que apresentou altos níveis de FDN $(84,0 \%)$ e de lignina (1,4\%). Provavelmente, o teor médio de proteína nas dietas $(6,8 \%)$, tenha afetado o consumo dos animais neste trabalho. Almeida et al. (1999) relataram consumo de 2,32\% PV para dietas com 7,35\% de PB e observaram aumento do consumo de matéria seca quando as dietas apresentavam teores de $14,55 \%$ de PB.

Os valores de consumo são superiores aos relatados por Vermorel et al. (1997) de 5,78 kg MS/dia e 58,2 $\mathrm{g} \mathrm{MS} / \mathrm{kg} \mathrm{PV}{ }^{0,75}$, em cavalos adultos castrados da raça Standardbred, e $501 \pm 57 \mathrm{~kg}$ de peso vivo, consumindo dieta mista de feno e concentrado e relação volumoso e concentrado de 70:30. Entretanto, os valores são inferiores aos observados por Araújo (1999), de 1,96 e $2,11 \%$ PV em matéria seca de dietas mistas para eqüinos adultos com peso médio de $336 \mathrm{~kg}$, quando restringiram a ingestão em $80 \%$ do consumo voluntário. Oliveira (1995) observou consumos de 85,7 e 100,8 kg $\mathrm{MS} / \mathrm{kg} \mathrm{PV} 0,75$ ou 2,3 e $2,6 \% \mathrm{PV}$, em potros alimentados com capim-elefante adicionado a $50 \%$ de milho triturado ou capim-elefante adicionado a $35 \%$ de milho triturado e $15 \%$ de farelo de soja, respectivamente.

A ingestão média diária de PB foi de $1,24 \mathrm{~g} / \mathrm{kg}$ PV, sendo a recomendação do NRC (1989) para animais em mantença de $1,3 \mathrm{~g} / \mathrm{kg}$ PV (Tabela 3 ). O consumo

Tabela 2 - Valores médios de peso vivo (PV) e consumo de matéria seca (CMS), expresso em kg MS/dia, \%PV e peso metabólico (CPM), de éguas alimentadas com dietas com diferentes níveis de substituição do MDPS pelo FVA

Table 2 - Average value of weight body (BW) and dry matter intake (DMI), expressed as $\mathrm{kg} D M /$ day, \% BW and metabolic weight (MWI), of mares fed diets with increasing replacement levels of CCM with MPM

\begin{tabular}{|c|c|c|c|c|c|c|}
\hline \multirow[b]{2}{*}{ Item } & \multicolumn{4}{|c|}{$\begin{array}{l}\text { Nível de substituição (\%) } \\
\text { Replacementlevel }\end{array}$} & \multirow[b]{2}{*}{$\begin{array}{l}\text { Média } \\
\text { Mean }\end{array}$} & \multirow[b]{2}{*}{$\mathrm{CV}(\%)^{1}$} \\
\hline & 0 & 33 & 66 & 100 & & \\
\hline $\begin{array}{l}\mathrm{PV}(\mathrm{kg}) \\
B W\end{array}$ & 398,25 & 409,25 & 367,75 & 393,44 & 392,17 & 6,58 \\
\hline $\begin{array}{l}\text { CMS (kg/dia) } \\
D M I\end{array}$ & 6,72 & 7,37 & 6,57 & 7,43 & 7,02 & 13,70 \\
\hline $\begin{array}{l}\text { CMS }(\% \mathrm{PV}) \\
D M I\end{array}$ & 1,72 & 1,80 & 1,80 & 1,89 & 1,80 & 12,03 \\
\hline $\begin{array}{l}\text { CPM } \\
\left(\mathrm{g} \mathrm{MS} / \mathrm{kg} \mathrm{PV}^{0,75}\right) \\
M W I\end{array}$ & 75,99 & 80,58 & 78,46 & 84,34 & 79,84 & 12,58 \\
\hline
\end{tabular}

1 Coeficiente de variação (Coefficient of variation). 
Tabela 3 - Consumo diário de nutrientes de éguas alimentadas com dietas com diferentes níveis de substituição do MDPS pelo FVA

Table 3 - Daily nutrients intake (g/day) of mares fed diets with increasing replacement levels of CCM with MPM

\begin{tabular}{|c|c|c|c|c|c|c|}
\hline \multirow[b]{2}{*}{$\begin{array}{l}\text { Consumo de nutrientes } \\
\text { Nutrients intake }\end{array}$} & \multicolumn{4}{|c|}{$\begin{array}{l}\text { Nível de substituição(\%) } \\
\text { Replacement level }\end{array}$} & \multirow[b]{2}{*}{$\begin{array}{l}\text { Média } \\
\text { Mean }\end{array}$} & \multirow[b]{2}{*}{$\mathrm{CV}(\%)^{1}$} \\
\hline & 0 & 33 & 66 & 100 & & \\
\hline $\begin{array}{l}\text { Proteína bruta (g/dia) } \\
\text { Crude protein (g/day) }\end{array}$ & 460,3 & 508,5 & 454,4 & 512,5 & 483,9 & 15,15 \\
\hline $\begin{array}{l}\text { Proteína digestível (g/dia) } \\
\text { Digestible protein }\end{array}$ & 258,8 & 294,7 & 250,9 & 297,7 & 275,5 & 17,14 \\
\hline $\begin{array}{l}\text { Fibra detergente neutro (g/dia) } \\
\text { Neutral detergent fiber }\end{array}$ & 3354,1 & 3743,3 & 3264,8 & 3702,7 & 3516,2 & 16,03 \\
\hline $\begin{array}{l}\text { Fibra detergente ácido (g/dia) } \\
\text { Acid detergent fiber }\end{array}$ & 1788,9 & 2080,5 & 1836,2 & 2081,1 & 1946,7 & 16,41 \\
\hline $\begin{array}{l}\text { Energia digestível (Mcal/dia) } \\
\text { Digestible energy }\end{array}$ & 9,91 & 9,27 & 7,78 & 9,54 & 9,13 & 18,76 \\
\hline
\end{tabular}

1 Coeficiente de variação (Coefficient of variation).

de FDN e FDA foi elevado com a inclusão do FVA na dieta, de 3354,1 para $3702,7 \mathrm{~g} /$ dia de FDN e de 1788,9 para 2081, $1 \mathrm{~g} /$ dia de FDA.

Considerando os valores médios dos coeficientes de digestibilidade da energia e energia bruta deste trabalho, os valores de ED não diferiram entre as dietas $(\mathrm{P}>0,05)$ sendo de 9,91, 9,27, 7,78 e 9,54 Mcal, para dietas com níveis de substituição 0,33,66 e 100\% de MDPS por farelo de vagem de algaroba, respectivamente. Estes valores foram, em média, 30,4\% inferiores às exigências do NRC (1989), estimadas para eqüinos em mantença com peso médio de $392,2 \mathrm{~kg}$. O menor nível de consumo de ED está relacionado à baixa qualidade do feno fornecido aos animais.

$\mathrm{Na}$ Tabela 4, podem ser observados os valores médios dos coeficientes de digestibilidade da matéria seca (CDMS), matéria orgânica (CDMO), proteína bruta (CDPB), fibra em detergente neutro (CDFDN), hemicelulose (CDHCEL), fibra em detergente ácido (CDFDA) e energia bruta (CDEB) das dietas.

Não foram observadas diferenças significativas nos coeficientes de digestibilidade da matéria seca, matéria orgânica, proteína bruta e hemicelulose entre as dietas, que apresentaram valores médios de 49,15, $50,18,56,89$ e $35,43 \%$, respectivamente, para as dietas com níveis de substituição do MDPS pelo farelo de vagem de algaroba de 0, 33, 66 e 100\%.

Almeida et al. (1999), compilando dados de 93 trabalhos realizados com dietas mistas de gramíneas e concentrado para eqüinos, relataram os seguintes coeficientes de digestibilidade: $61,34 \%$ para CDMS; 66,44\% para CDMO; 69,88\% para CDPB; $61,46 \%$ para $\mathrm{CDEB} ; 48,27 \%$ para $\mathrm{CDFDN} ; 37,93 \%$ para CDFDA; e 59,65\% para CDHCEL. Os valores de digestibilidade registrados neste trabalho estão, em média, abaixo destes valores. Apesar das diferenças entre dietas e condições experimentais, em geral, a magnitude dos coeficientes de digestibilidade pode ter sido afetada pela qualidade do feno utilizado, que este se caracterizou com baixa qualidade, possuindo teor de $\mathrm{PB}$ de apenas $4,5 \%$ e elevados percentuais de FDN e FDA, de 67,7 e 36,9\%, respectivamente.

Observaram-se efeitos da substituição do MDPS pelo farelo de vagem de algaroba nos coeficientes de digestibilidade aparente da fração fibrosa e energia $(\mathrm{P}<0,05)$, segundo as equações CDFDN: $\hat{\mathrm{Y}}=28,089$. 0,0853X $\left(\mathrm{R}^{2}=37,9\right)$; CDFDA: $\hat{\mathrm{Y}}=7,751+0,0891 \mathrm{X}$ $0,002 X^{2}\left(R^{2}=52,6\right) ; C D E B: \hat{Y}=43,402-0,2441 X+$ $0,0019 X^{2}\left(R^{2}=62,9\right)$, respectivamente, em que $X$ refere-se ao nível de substituição. Na Figura 1, pode ser observado o efeito quadrático nos valores dos coeficientes de digestibilidade da FDA, em função da substituição crescente do MDPS pelo farelo de vagem de algaroba. De acordo com a equação obtida, o ponto máximo de digestibilidade da FDA $(18,7 \%)$ pode ser obtido com $22,3 \%$ de substituição. O maior valor do CDFDN $(28,1 \%)$ ocorreu na dieta sem a substituição do MDPS pelo farelo de vagem de algaroba.

A vagem da algarobeira tem em sua composição $28,1 \%$ de casca caracterizada como dura e fibrosa, com teores de FB, de $31,6 \%$ e de FDA, de 37,5\% (Del 
Tabela 4 - Coeficientes de digestibilidade aparente da MS, MO, PB, HCEL, FDN, FDA e EB de dietas com feno de coastcross e concentrado (60:40) com diferentes níveis de FVA em substituição ao MDPS

Table 4 - Coefficients of apparent digestibility of DM, OM, CP, HCEL, NDF, ADF and GE of diets with coastcross hay and concentrate (60:40) with increasing replacement levels of CCM with MPM

\begin{tabular}{|c|c|c|c|c|c|c|}
\hline \multirow[b]{2}{*}{ Item } & \multicolumn{4}{|c|}{$\begin{array}{l}\text { Nível de substituição } \\
\text { Replacement level }\end{array}$} & \multirow[b]{2}{*}{$\begin{array}{l}\text { Média } \\
\text { Mean }\end{array}$} & \multirow[b]{2}{*}{$\mathrm{CV}(\%)^{1}$} \\
\hline & 0 & 33 & 66 & 100 & & \\
\hline \multicolumn{7}{|c|}{$\begin{array}{l}\text { Coeficiente de digestibilidade aparente }(\%) \\
\text { Coefficient of apparent digestibility }\end{array}$} \\
\hline $\operatorname{MS}(D M)$ & 51,35 & 50,05 & 47,66 & 47,54 & 49,15 & 4,86 \\
\hline $\mathrm{MO}(O M)$ & 52,61 & 51,10 & 48,72 & 48,30 & 50,18 & 4,62 \\
\hline $\mathrm{PB}(C P)$ & 56,28 & 57,65 & 55,38 & 58,24 & 56,89 & 7,38 \\
\hline HCEL & 40,00 & 34,43 & 30,17 & 37,13 & 35,43 & 12,65 \\
\hline $\operatorname{FDN}(N D F)$ & 27,48 & 27,67 & 19,52 & 20,70 & 1 & 16,61 \\
\hline $\mathrm{FDA}(A D F)$ & 16,50 & 22,26 & 11,24 & 7,90 & -2 & 27,33 \\
\hline $\mathrm{EB}(G E)$ & 43,30 & 37,70 & 35,20 & 37,93 & & 7,17 \\
\hline
\end{tabular}

$1 Y=28,089-0,0853 \times\left(R^{2}=37,9\right)(p=0,0105)$.

$2 Y=17,751+0,0891 x-0,002 x^{2}\left(R^{2}=52,6\right)(p=0,0468)$.

$3 Y=43,402-0,2441 x+0,0019 x^{2} \quad\left(R^{2}=62,9\right)(p=0,0147)$.

4 Coeficiente de variação (Coefficient of variation).

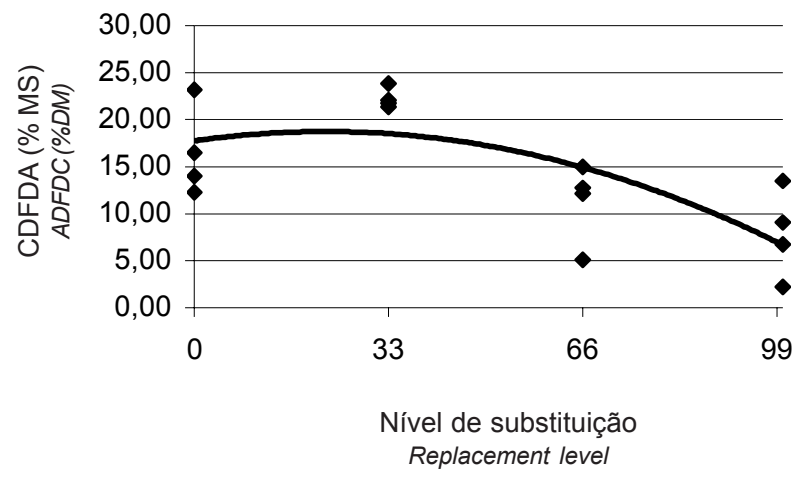

Figura 1 - Coeficiente de digestibilidade aparente da FDA em dietas compostas por feno de coastcross e concentrado (60:40) com diferentes níveis de FVA em substituição ao MDPS.

Figure 1 - Apparent digestibility coefficients of ADF of diets with Coast cross hay and concentrate (60:40) with increasing replacement levels of MPM with CCM.

Valle et al., 1983). No presente trabalho, foram observados valores de $25,26 \%$ de FDN e $18,89 \%$ de FDA no farelo de vagem de algaroba. É possível que os componentes fibrosos, presentes em abundância na casca da algaroba, possuam baixa digestibilidade no trato digestivo de eqüinos. Talpada \& Shukla (1988), utilizando a vagem de algaroba triturada (VAT) em dietas para vacas em lactação, não detectaram reduções significativas na digestibilidade dos compostos fibrosos. Outros trabalhos com ruminantes reporta- ram ganhos de peso (Ravilaka et al., 1995; Silva et al., 1982) e melhora na produção e qualidade do leite (Nobre, 1982), quando se utilizou a vagem de algaroba triturada.

Embora estes resultados sejam contraditórios, sabe-se que a eficiência na utilização de compostos fibrosos é inferior em eqüinos quando comparada aos ruminantes (Frape, 1986; Cymbaluk, 1990). As características principais que tornam esse fato realidade são a diferença entre as quantidades e espécies das bactérias celulolíticas existentes no ceco e cólon, em relação ao rúmen e a maior taxa de passagem da digesta observada nos eqüinos (De Fombelle et al., 1999; Frape, 1986; LaCasha et al, 1999). O aumento da ingestão de FDN e FDA pode afetar a digestibilidade de compostos fibrosos por meio da elevação da taxa de passagem do conteúdo digestivo (Oliveira, 1995; LaCasha et al., 1999), podendo resultar em redução da digestibilidade de FDN e FDA quando o nível de substituição de FVA nas rações concentradas for maior, pois as rações com maiores níveis de substituição também apresentaram maiores teores destes compostos $(24,6 ; 26,5 ; 24,6$; e $23,6 \%$ de FDN e 11,9 ; 15,$7 ; 15,5$ e $14,9 \%$ de FDA, nos níveis $0,33,66$ e $100 \%$, respectivamente).

Na Figura 2, pode ser observado o efeito quadrático no CDEB em função da substituição do MDPS pelo FVA. O valor máximo do coeficiente de digestibilidade foi de 43,4\% na dieta sem a FVA. Em ruminantes, Barros \& Queiróz Filho (1982) e Talpada \& Shukla 


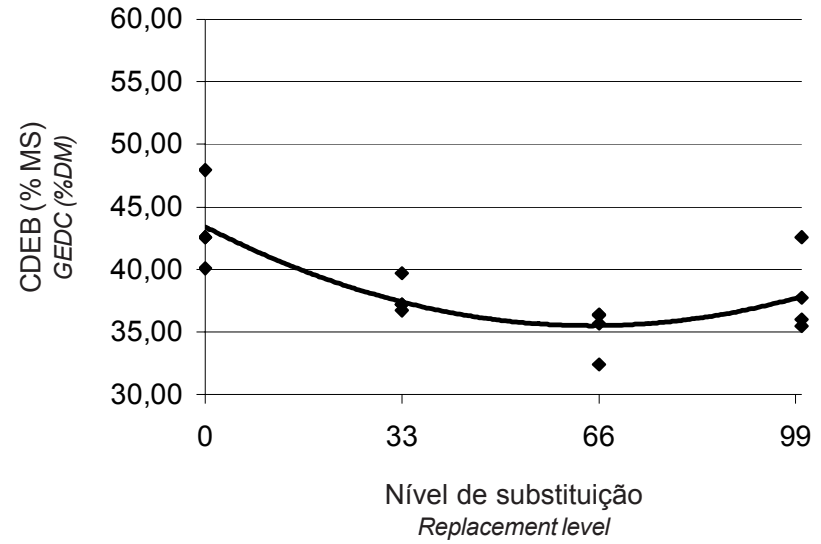

Figura 2 - Coeficiente de digestibilidade aparente da EB em dietas compostas por feno de Coast cross e concentrado (60:40) com diferentes níveis de FVA em substituição ao MDPS.

Figure 2 - Apparent digestibility coefficient of GE of diets with Coastcross hay and concentrate (60:40) with increasing replacement levels of MPM with CCM.

(1988) não observaram efeitos sobre o CDEB quando forneceram vagem de algaroba triturada no concentrado de carneiros e de vacas lactantes, respectivamente.

Os principais produtos da fermentação dos carboidratos estruturais, tanto em eqüinos quanto em ruminantes, são os ácidos graxos voláteis que constituem a principal fonte de energia para os eqüinos em mantença. A digestibilidade destes carboidratos está, portanto, diretamente relacionada à curva de resposta da energia digestível, observando-se redução no CDEB de até $64,2 \%$ em função da substituição do MDPS pelo farelo de vagem de algaroba.

A substituição do MDPS pelo FVA em dietas para eqüinos em mantença, considerando os resultados de digestibilidade nas condições deste trabalho, pode ser feita em até $100 \%$, a despeito da redução na digestibilidade, principalmente dos componentes fibrosos, o que não parece comprometer a viabilidade biológica desta substituição.

\section{Conclusões}

Nas condições do presente trabalho, o farelo de vagem de algaroba pode substituir em até $100 \%$ o milho desintegrado com palha e sabugo em dietas para eqüinos em mantença, sem afetar o consumo de matéria seca e de energia digestível e os coeficientes de digestibilidade da matéria seca, matéria orgânica, proteína bruta e hemicelulose.

A substituição do milho desintegrado com palha e sabugo pelo farelo de vagem de algaroba proporcionou redução nos coeficientes de digestibilidade da FDN e FDA, reduzindo, como conseqüência, o aproveitamento energético da ração contendo altos níveis de farelo de vagem de algaroba. Entretanto, estes efeitos não descartam o uso do farelo de vagem de algaroba nas dietas de eqüinos.

$\mathrm{O}$ farelo de vagem de algaroba pode se tornar um ingrediente dietético e economicamente viável para eqüinos na região Nordeste do Brasil, a partir da disseminação e fomento de sua produção, respaldados na pesquisa científica.

\section{Agradecimento}

À FAPESP, pelo financiamento do projeto de pesquisa e à Universidade Federal Rural do Rio de Janeiro, que possibilitou a realização do experimento.

\section{Literatura Citada}

ALMEIDA, M.I.V.; FERREIRA, W.M.; ALMEIDA, F.Q. et al. Composição química e predição do valor nutritivo de dietas para eqüinos. Revista Brasileira de Zootecnia, v.28, n.6, p.1268-1278, 1999.

ARAÚJO, K.V. Métodos para determinação da digestibilidade aparente dos nutrientes em eqüinos. Lavras: Universidade Federal de Lavras, 1999. 155p. Dissertação (Mestrado em Zootecnia) - Universidade Federal de Lavras, 1999.

BARROS, N.A.M.T.; QUEIRÓZ FILHO, J.L. Efeitos na substituição progressiva do melaço por vagens de algaroba (Prosopis juliflora (Sw) D.C.) na alimentação de ruminantes. In: SIMPÓSIO BRASILEIRO SOBRE ALGAROBA, 1., 1982, Natal. Anais... Natal: EMPARN, 1982. p.385-407.

CYMBALUK, N.F. Comparison of forage digestion by cattle and horses. Canadian Journal of Animal Science, v.70, p.601610,1990 .

De FOMBELLE, A.; JACOTOT, E.; DROGOUL, C. et al. Effect of the hay:grain ratio on digestive physiology and microbial ecosystem in ponies. In: EQUINE NUTRITION AND PHYSIOLOGY SYMPOSIUM, 16., Raleigh, 1999. Proceedings... Raleigh: ENPS, 1999. p.151-154.

DEL VALLE, F.R.; ESCOBEDO, M.; MUÑOZ, M.J. et al. Chemical and nutritional studies on mesquite beans (Prosopis juliflora). Journal of Food Science, v.48, p.914-919, 1983.

FRAPE, D. L. Equine nutrition and feeding. London: Longman Scientifc \& Technical, 1986. 373p.

GOMES, P. A algarobeira. Rio de Janeiro: Ministério da Agricultura, 1961. 49p (SIA 865)

LaCASHA, P.A.; BRADY, H.A.; ALLEN, V.G. et al. Voluntary intake, digestibility, and subsequent selection of Matua bromegrass, Coastal Bermudagrass, and Alfafa 
hays by yearling horses. Journal of Animal Science, v.77, p.2766-2773, 1999.

MARTIN-ROSSET, W. La alimentacion de los caballos. Traduzido por Dr. Antonio Conceillón Martinez, 1993. p.174.

MERCHEN, N.R. Digestion, absortion and excretion in ruminants. In: CHURCH, D.C. (Ed.) The ruminal animal. Digestive physiology and nutrition. Englewood Cliffs: Prentice Hall, 1993. p.172-201.

MEYER, H. Alimentação de cavalos. São Paulo: Varela, 1995. $303 p$.

NOBRE, F.V. Algaroba na alimentação de vacas em lactação. Recife: Universidade Federal de Pernambuco, 1982. 74p. Dissertação (Mestrado em Zootecnia) - Universidade Federal de Pernambuco, BNB - ETENE, 1982. (Título original: "Substituição do farelo de trigo (Triticum vulgare) pelo fruto triturado da algarobeira (Prosopis juliflora (Sw) D.C.), na alimentação de vacas em lactação".

NATIONAL RESEARCH COUNCIL - NRC. Nutrient requirements of horses. 5.ed.rev. Washington, D.C.: National Academy of Sciences, 1989. 100p.

OLIVEIRA, A.A.M.A. Digestão total e pré-cecal dos nutrientes em potros fistulados no íleo. Viçosa, MG: Universidade Federal de Viçosa, 1995. 92p. Dissertação (Mestrado em Zootecnia) - Universidade Federal de Viçosa, 1995.

RAVILAKA, K.; PATEL, A.M.; MURTHY, K.S. et al. Growth efficiency in feedlot lambs on Prosopis juliflora based diets. Small Ruminant Research, v.16, p.227-231, 1995.

SILVA, D.J.; QUEIROZ, A.C. Análise de alimentos: métodos químicos e biológicos. 3.ed. Viçosa, MG: Universidade Federal de Viçosa, 2002. 235p.
SILVA, D.S.; LEITÃO, S.C.; OLIVEIRA FILHO, J.J. Substituição do farelo de trigo (Triticum vulgare Komarnitzky) pelo fruto triturado da algarobeira (Prosopis juliflora (S.w.) D.C.). In: SIMPÓSIO BRASILEIRO SOBRE ALGAROBA, 1., 1982, Natal. Anais... Natal: EMPARN, 1982. p.361-379.

STATISTICAL ANALYSIS SISTEM - SAS. SAS/STAT ${ }^{\circledR}$ user's guide: version 6. 5.ed. Cary: 1989. v.2, 846p.

STEIN, R.B.S. Avaliação de métodos para determinação da digestibilidade aparente utilizando farelo de vagem de algaroba (Prosopis juliflora (Swartz) D.C.) em eqüinos. Pirassununga: Faculdade de Zootecnia e Engenharia de Alimentos. 2002. 69p. Dissertação (Mestrado em Zootecnia) Faculdade de Zootecnia e Engenharia de Alimentos/Universidade de São Paulo, 2002.

VERMOREL, M.; VERNET, J.; MARTIN-ROSSET, W. Digestive and energy utilization of two diets by ponies and horses. Livestock Production Science, v.51, p.13-19, 1997.

TALPADA, P.M.; SHUKLA, P.C. Influence of feeding Prosopis juliflora pods on digestibility and balances in lactantes cows. Indian Journal of Animal Science, v.58, n.6, p.727-730, 1988.

Recebido em: 22/12/03

Aceito em: 17/01/05 